\title{
Prognostic factors in renal cell carcinoma: analysis of 227 patients treated at the Brazilian National Cancer Institute
}

Antonio A. Ornellas, Dennyson M. Andrade, Paulo Ornellas, Aristóteles Wisnescky, Aline B. de Santos Schwindt

Department of Urology, Brazilian National Cancer Institute (AAO, DMA, PO, AW), Rio de Janeiro, Brazil and Department of Pathology, Brazilian National Cancer Institute (ABSS), Rio de Janeiro, Brazil

\section{ABSTRACT}

Purpose: We evaluated the role of several prognostic factors in predicting death and/or progressive disease in patients with renal cell carcinoma.

Materials and Methods: Between 2004 and 2010, 227 consecutive patients with renal cell carcinoma underwent radical nephrectomy at our Institute. All histological specimens were examined by the same pathologist. We considered certain histological parameters, including histological subtype, conventional Fuhrman grade, presence of sarcomatoid features, adrenal gland infiltration, invasion of the perinephric fat, vascular embolization, collecting system invasion, presence or absence of tumour necrosis $(0 \%, 1 \%$ to $49 \%$, or $50 \%$ or greater) and regional lymph node metastasis.

Results: Variables significantly associated with death and/or progressive disease on univariate analysis were histological subtype $(p=0.006)$, Fuhrman grade $(p<$ $0.0001)$, tumor necrosis ( $p=0.009)$, perinephric fat invasion $(p=0.002)$, vascular embolization $(p=0.0002)$, presence of lymph node involvement $(p<0.002)$, tumor size $(p=0.0006)$, TNM stage $(p<0.00001)$ and presence of metastasis $(p<$ 0.00001). In the multivariable model histological subtype, tumor necrosis, lymph node involvement and presence of metastasis were independent risk factors for disease-free survival ( $\mathrm{p}=0.011,0.042,0.025$ and $\mathrm{p}<0.0001$, respectively).

Conclusion: Histological subtype, tumor necrosis, lymph node involvement and presence of metastasis proved to be independent prognostic factors for disease-free survival. Therefore, the presence and rate of tumor necrosis should always be informed by the pathologist and lymphadenectomy should be performed in all patients.

\section{ARTICLE INFO}

\section{Key words:}

Kidney; neoplasms; outcomes; nephrectomy

Int Braz J Urol. 2012; 38: 185-94

Submitted for publication: June 14, 2011

Accepted after revision:

August 28, 2011

\section{INTRODUCTION}

In the United States, renal cancer represents respectively the 7 th and 9 th most common malignancy in men and in women, accounting for about 3\% of cancer deaths. In this country, the National Cancer for Health Statistics Insti- tute (NCHSI) (1) estimated that 57,760 new cases would be diagnosed and 12,980 deaths would ocurr in 2009. In 2002, the global estimate was 20,800 new cases and 10,200 deaths, accounting for about $1.9 \%$ of tumors in general. The highest incidences occurred in North America, Australia/New Zealand and Europe, with lower rates in 
Africa, Asia and the Pacific (2). We have in our national literature a lack of data concerning the general characteristics of patients with renal malignancy, since the disease is not among the 10 most frequent tumor types annually reported by the Brazilian National Cancer (3). The Brazilian Society of Urology, through the ENCARE study, initiated a project aimed to carry out an epidemiological study of renal cancer in our country. Recently complete data from this study was published (4). The current work aims to show, from a survey of factors relevant to disease, the profile of patients with this type of pathology at the $\mathrm{Na}-$ tional Cancer Institute over the past six years.

\section{MATERIALS AND METHODS}

Between 2004 and 2010, 227 consecutive patients including 116 males (51\%) and $111 \mathrm{fe}-$ males (49\%) with renal cell carcinoma (RCC) were referred to our Institute and treated with curative intent by radical nephrectomy. Other 26 patients, 14 males (53.8\%) and 12 females (46.2\%) with normal contralateral kidneys underwent partial nephrectomy with the same curative intent. These last patients were excluded of this study because most of them were operated after 2009 which hampered the analysis of their survival. After obtaining institutional board approval, pathological data of these patients were prospectively evaluated. Data collected by tumor registrars on all tumors included standard tumor registry data elements, such as patient age, gender, diagnosis date, initial therapy, follow-up, subsequent therapy and outcome. Patient follow-up data were gathered from medical charts at our institution and when necessary through contact with the patient family. We retrospectively reviewed the charts to determine dates of recurrence and death, as well as cause of death. Mean and median patient age was 58 and 60 years at diagnosis (range 2 to 83). Follow-up was evaluated in 223 of 227 patients. Median follow-up was 28 months (range 0 to 88).We excluded from the analysis of survival curves 4 patients with less than 1 month of clinical follow-up.

Study inclusion criteria were: surgical resection of pathologically confirmed renal cell carcinoma, adequate tissue available for pathological reevaluation, and adequate radiographic and/or clinical follow-up data available. Exclusion criteria were: pathologically confirmed urothelial carcinoma or any benign lesion and tissue unavailable for accurate reevaluation.

To facilitate statistical comparisons the patients were grouped into four groups of staging: Stage I (T1 No M0), Stage II (T2 No M0), Stage III (T3 No M0, T1, T2, T3 N1 M0) and Stage IV (T4 N0, N1 M0 any T N2 M0 any T any N M1).

The weight and tumor size were recorded from surgical pathology reports. Pathological material were re-reviewed by a single pathologist (ABSS) blinded to clinical outcome data.

The data captured were histological type according to the 2004 WHO classification. The pathological variables studied were histological subtype, conventional Fuhrman grade, presence of sarcomatoid features, adrenal gland infiltration, invasion of the perinephric fat, vascular embolization, collecting system invasion, presence or absence of tumour necrosis $(0 \%, 1 \%$ to $49 \%$, or $50 \%$ or greater) and regional lymph node metastasis. These factors were gathered together in the universally used 2002 AJCC TNM staging classification system. Not all the parameters chosen for analysis were available for all patients. For example, not all patients underwent lymphadenectomy, thus preventing the histological analysis of lymph nodes in these cases. Also some histological parameters could not be evaluated in all patients by lack of information on pathological material reviewed by the pathologist.

The data obtained were recorded on a standard research form and filled in a database. Analysis was performed using SPSS ${ }^{\circledR}$. The associations of qualitative factors with death and/or presence of progressive disease were done with the chi-square test. Independent factors related to death and/or progressive disease were identified by linear regression analysis with $\mathrm{p}<0.05$ considered statistically significant. Disease-free survival (DFS) was defined as time to the date of progression of disease and/or to the date of death from disease. The Kaplan-Meier technique was used to evaluate DFS and the log rank test was used to compare survival curves with $p<0.05$ as the significance cutoff. 


\section{RESULTS}

When our patients were stratified according clinical stage there were $73(32.1 \%)$ with stage I, 68 (29.9\%) with stage II, 66 (29\%) with stage III and $15(6.6 \%)$ with stage IV. We were unable to evaluate the clinical staging in the medical records of five patients.

When tumors were stratified according to size there were 22 tumors $(9.7 \%)$ with $4 \mathrm{~cm}$ or less in diameter, 79 tumors (34.8\%) larger than 4 $\mathrm{cm}$ and lesser than $7 \mathrm{~cm}$ and 124 tumors (54.6\%) larger than $7 \mathrm{~cm}$ in diameter. We were unable to measure the diameter of the tumor in 2 patients.

Histological findings confirmed renal cell carcinoma (RCC) in all 227 patients. Of the 227 specimens $165(72.7 \%)$ were identified as clear cell carcinoma, $24(10.6 \%)$ as chromophobe tumor, $11(4.8 \%)$ as papillary tumor type I, and 13 (5.7\%) as papillary tumor type II. One group of 12 patients (5.3\%) presented sarcomatoid features and were studied separately. Sarcomatoid RCC, initially considered a distinct subtype, is now recognized as a high-grade transformation that can arise in any subtype of RCC. The remaining 2 cases were a neuroendocrine tumor and a tumor of unclassified mesenchymal lineage. 46 patients (20.3\%) had metastatic disease, 33 (14.5\%) died of RCC and 11 (4.8\%) were alive but showing progression of the disease when the survey was done.

Regarding Fuhrman grade 24 patients (10.6\%) were classified as grade I, $97(42.7 \%)$ as grade II, 61 (26.9\%) as grade III and 38 (16.7\%) as grade IV. In the specimens of seven patients we were unable to classify according to Fuhrman grade due to reasons explained in the section Materials and Methods.

Invasion of adrenal gland occurred in no more than 7 patients. Perinephric fat invasion, collecting system invasion and vascular embolization were present respectively in the specimens of $62(27.3 \%), 38(16.7 \%)$ and $69(30.4 \%)$ patients.

Among the specimens, 108 (47.6\%) showed tumor necrosis, which was identified in 77 of 165 cases $(46.7 \%)$ of clear cell, 6 of 11 (54.5\%) of papillary type I, 8 of $13(61.5 \%)$ of papillary type II, 6 of 24 (25\%) of chromophobe and in $9(75 \%)$ of 12 specimens with sarcomatoid features. A total of 118 patients (52\%) had no tumor necrosis, 61 (26.9\%) had less than 50\% and $47(20.7 \%)$ had $50 \%$ or greater. In one patient it was not possible to assess the presence or absence of tumor necrosis.

Lymph node involvement was present in 22 of 130 patients. Metastases occurred in 46 of our 227 patients. Death and/or progressive disease results significantly correlated with histological subtype $(\mathrm{p}=0.006)$, Fuhrman grade $(\mathrm{p}<$ 0.0001), tumor necrosis $(p=0.009)$, perinephric fat invasion $(p=0.002)$, vascular embolization ( $p$ $=0.0002)$, presence of lymph node involvement $(\mathrm{p}<0.002)$, tumor size $(\mathrm{p}=0.0006)$, TNM stage $(\mathrm{p}<0.00001)$ and presence of metastasis $(\mathrm{p}<$ 0.00001 ). Presence of adrenal invasion or collecting system invasion was not significant ( $p=0.14$ and $\mathrm{p}<0.083$ ). Only histological subtype, tumor necrosis, lymph node involvement and presence of metastasis proved to be independent predictive variables of disease-free survival on multivariate analysis $(\mathrm{p}=0.011,0.042,0.025$ and $\mathrm{p}<0.0001$, respectively, Table-1). Histological subtype, Fuhrman grade, the variable percent of tumor necrosis (TN), TN presence/absence, perinephric fat invasion, vascular embolization, presence of lymph node involvement, tumor size, TNM stage and presence of metastases, were also significantly associated with overall survival (OS).

Figure-1 shows the disease-free survival of patients in relation to histological subtype. Patients without tumor necrosis had better survival rates after 5 years than those with tumor necrosis ( $p<0.0001$, Figure-2). Log rank analysis also showed differences in 5-year disease survival curves according to the presence of lymph node involvement ( $p<0.0001$, Figure- 3 ) and presence of metastasis $(p<0.0001$, Figure- 4$)$

\section{COMMENTS}

The Brazilian National Cancer Institute receives many patients with large tumors who are not candidates for partial nephrectomy. In our evaluation we found only 26 patients undergoing partial nephrectomy. However most of them (18) were operated from 2009 until the end of the study. This has damaged our analysis of patient 
Figure 1 - Rate of disease-free survival after 5 years according to the various histological subtypes. The higher percentage of survival occurred in patients with chromophobe tumors and lower survival rate in patients with sarcomatoid features. (Kaplan-Meier log rank test $\mathrm{p}<\mathbf{0 . 0 0 0 1 )}$.

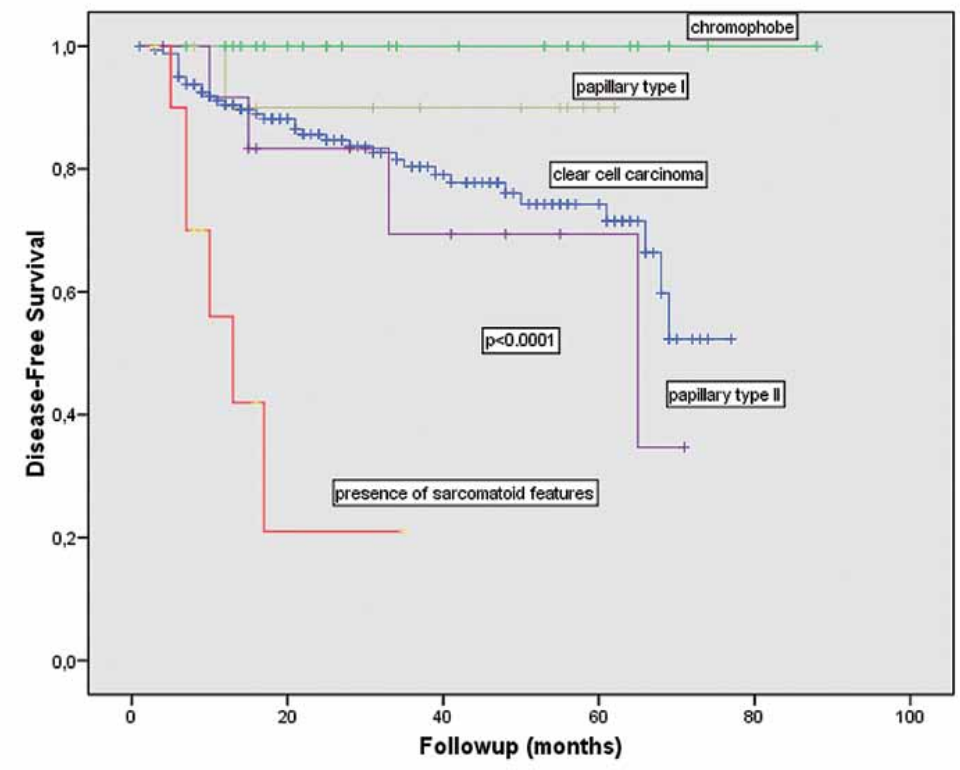

Figure 2 - 118 patients without tumor necrosis had higher 5-year survival than 61 with percentage of tumor necrosis less than $50 \%$ and 47 with percentage of tumor necrosis greater than $50 \%$. (Kaplan-Meier log rank test $\mathrm{p}<0.0001$ ).

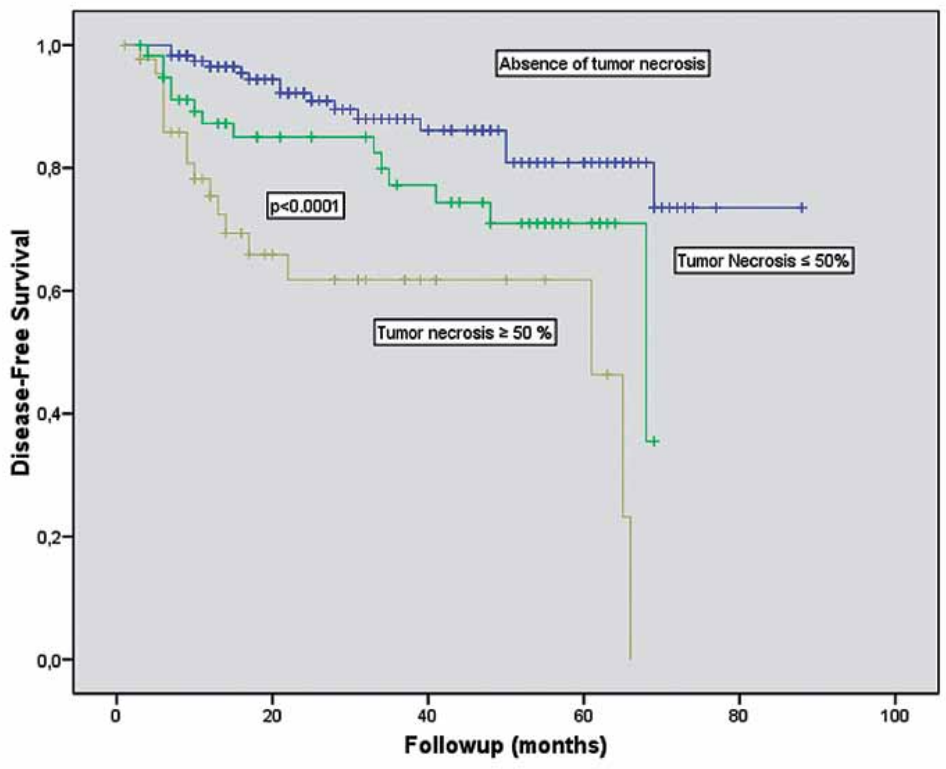




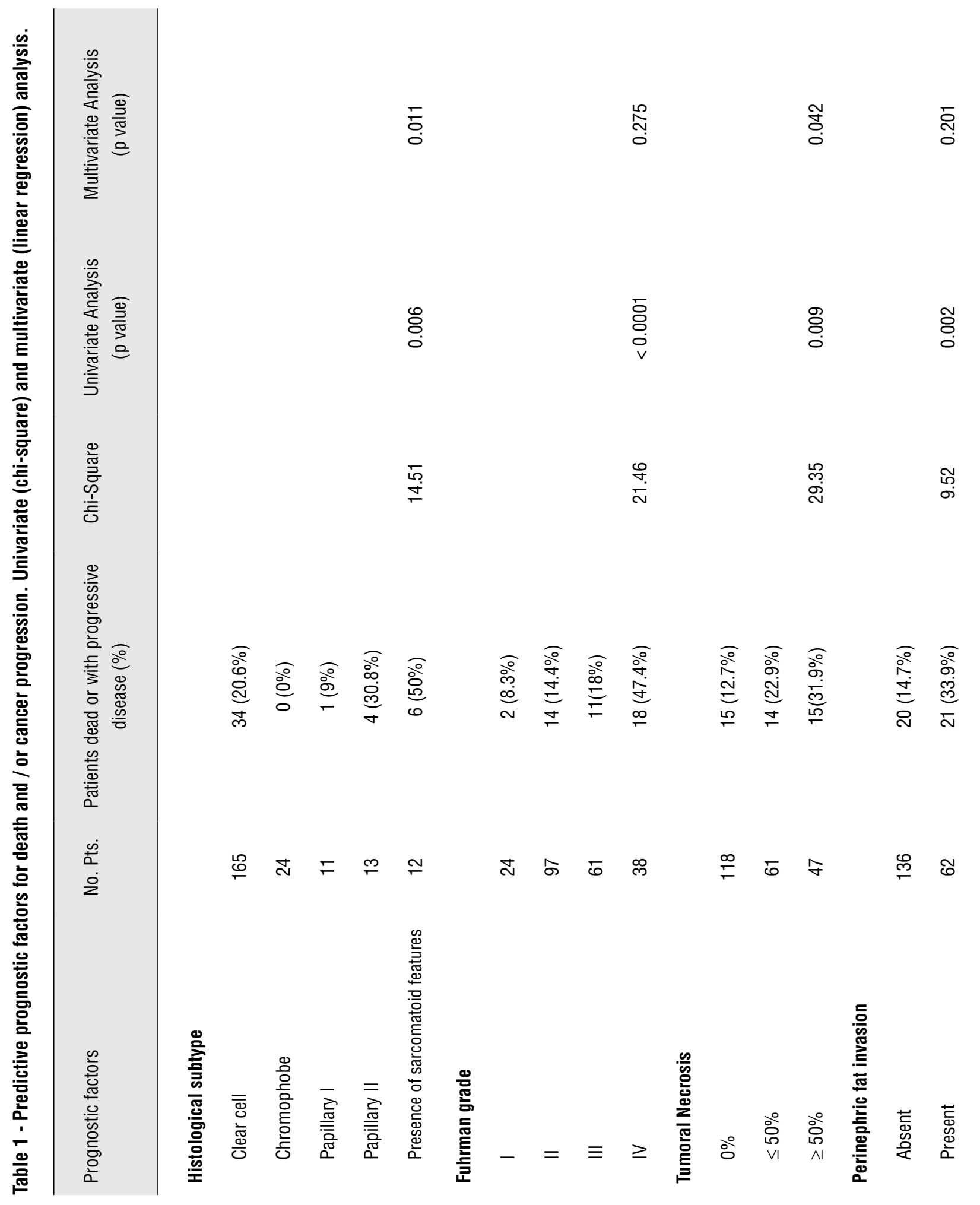


웅

迎

กิ

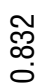

$\bar{c}$
0
0

ᄋ̊․․

$\begin{array}{ll}\text { ๓ } & \text { ิ } \\ 0 & \circ\end{array}$

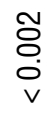

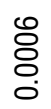

5
ㅇ
○.
v

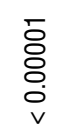

옴

$\stackrel{\oplus}{\underset{\leftarrow}{ர}}$

$\stackrel{\infty}{\sim}$

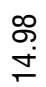

ठ
டे

స్

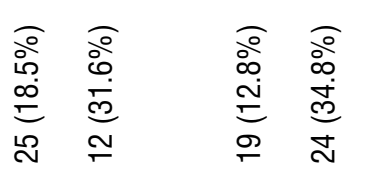

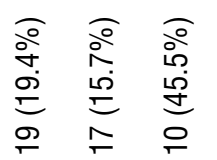

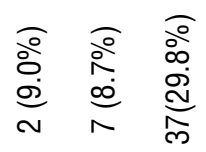

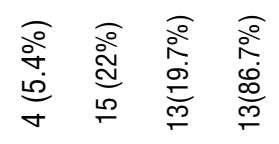

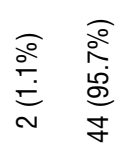

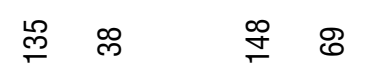

$\stackrel{\infty}{\circ}$ ล

$\approx হ \stackrel{1}{N}$

๓๐\&

Ðo g

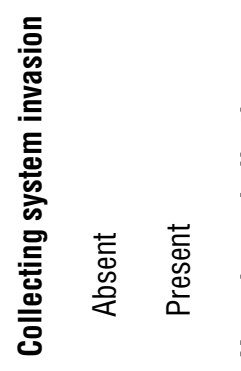

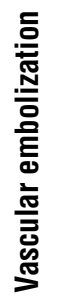

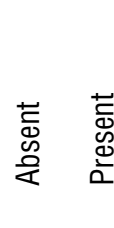

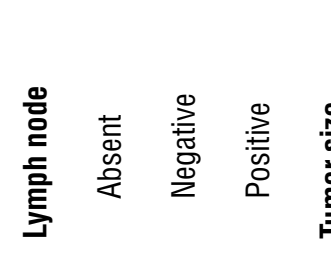

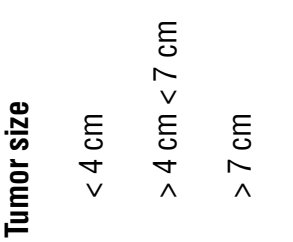

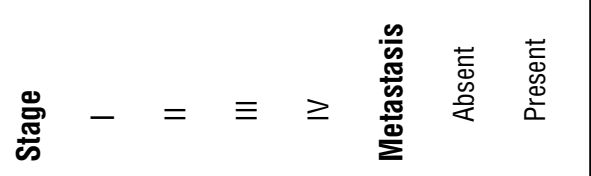


Figure 3 - 108 patients with negative lymph nodes had higher 5-year survival than 22 with positive lymph nodes. The 98 patients in whom no lymph nodes were assessed also had a disease-free survival at 5 years shorter than that of patients with negative lymph nodes. (Kaplan-Meier log rank test $\mathrm{p}<\mathbf{0 . 0 0 0 1 )}$.

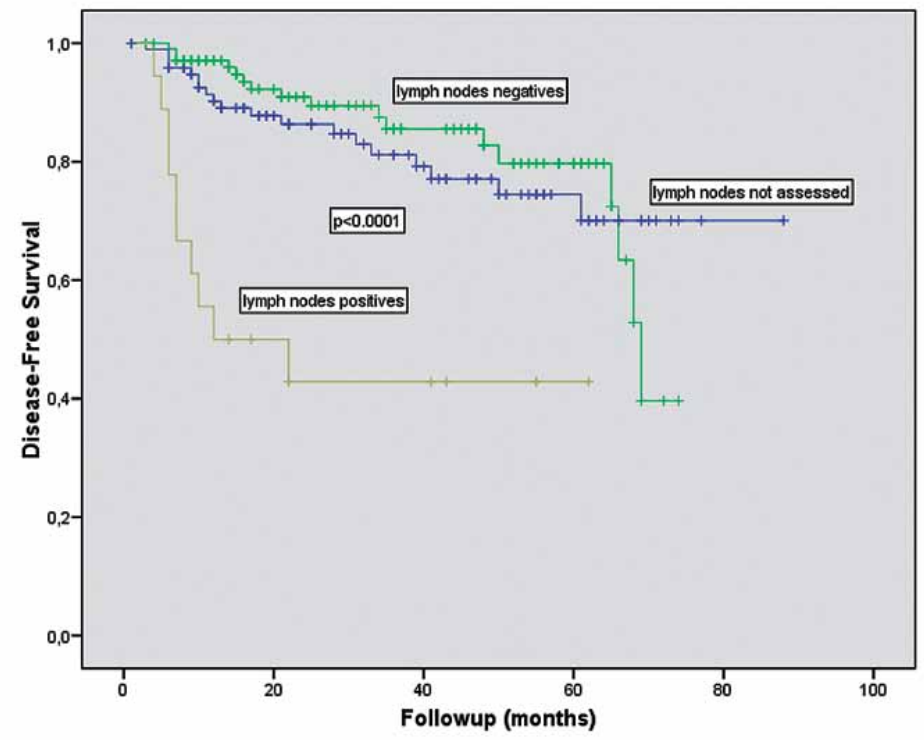

Figure 4 - Among 227 patients, 46 who had metastases had a worse 5-year survival rate. (Kaplan-Meier log rank test $p<0.0001$ ).

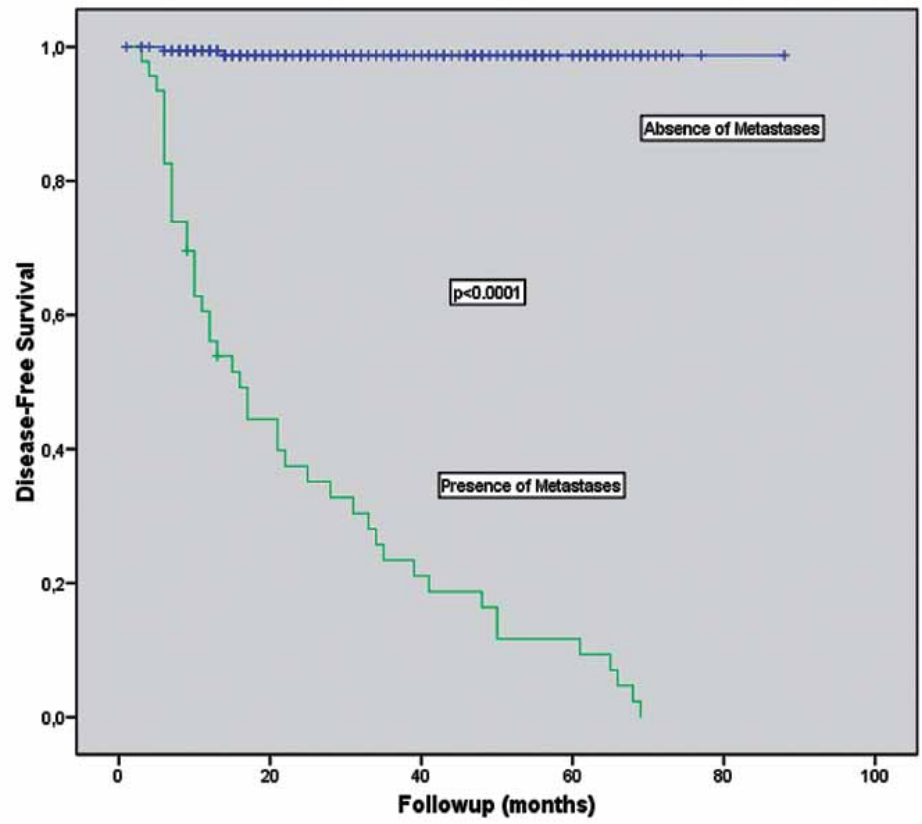


survival. We prefer to wait some time to publish our data regarding partial nephrectomy in patients with kidney cancer. Partial nephrectomy is indicated for patients with bilateral tumors or a solitary functioning kidney. The success rate is excellent with a cancer-specific survival ranging from $78 \%$ to $100 \%$. Although radical nephrectomy remains as standard treatment for localized tumors and normal contralateral kidney, growing number of authors has shown excellent results in these cases with nephron-sparing surgery since preservation of renal function is a prognostic factor for overall survival. For some authors partial nephrectomy must be the established treatment for T1a tumours $(<4 \mathrm{~cm})$ and an emerging standard treatment for $\mathrm{T} 1 \mathrm{~b}$ tumours $(4-7 \mathrm{~cm})$ provided that the operation is technically feasible and the tumour can be completely removed (5).

Our disease-free survival rates after 5 years for patients with clear cell, chromophobe, papillary type I and II RCC were 72.5\%, 100\%, $90 \%$, and $70 \%$ respectively. The presence of a sarcomatoid component was significantly associated with death of our patients with diseasefree survival rate of $21.7 \%$ after 35 months of follow-up (Figure-1). Many studies have shown a better prognosis for patients with chromophobe, papillary and conventional (clear cell) RCCs, respectively $(6,7)$. In a large series, Patard et al. (7) found a trend toward a better survival when clear cell, papillary, and chromophobe histologies were considered prognostic categories. However, in multivariate analysis, TNM stage and Fuhrman grade, but not histology, were retained as independent prognostic variables. Unlike in our series, histological subtype proved to be an independent predictive variable on multivariate analysis but this did not occur with Fuhrman grade and TNM stage (Table-1).

Death and/or progressive disease results significantly correlated with the size of the tumors but this parameter has not proved to have statistical significance on multivariate analysis. A recent study from Memorial Sloan-Kettering Cancer Center found that among patients with proven RCC, each $1 \mathrm{~cm}$ increase in tumor size increased the odds of having a tumor of high grade by $25 \%$ (8).
Only 7 of our patients presented adrenal invasion. Of them 3 died of the disease. The comparative analysis of survival of these patients was impaired due to the small number of patients. Han et al. (9) identified 27 patients with direct adrenal involvement from a universe of 1,087 undergoing nephrectomy. In this study, invasion of the adrenal gland remains a significant independent predictor of decreased survival on multivariate analysis.

Of our 62 patients with perinephric fat invasion, $21(33.8 \%)$ died of RCC and the 5-year disease-free survival rate was $40 \%$. Death and/ or progressive disease results significantly correlated when we compared patients with presence or absence of perinephric fat involvement. However these results were not significant for diseasefree survival on multivariate analysis (Table-1). Thompson et al. (10) studied 162 patients with perinephric fat invasion of whom 95 (59\%), died of RCC. The estimated 5-year disease-free survival rate was $50.9 \%$ for these patients.

We found a trend toward a worse prognosis in patients with collecting system invasion ( $p<0.083$ ). According to Anderson et al. (11), the presence of urinary collecting system invasion is independently associated with higher overall and disease-specific mortality in patients undergoing nephrectomy for pT3 RCC.

Tumor thrombi were identified at several sites in 69 patients. These patients had worse prognosis than those who did not have tumor thrombi. However, this parameter has no proved significant on multivariate analysis. According to Feifer et al. (12), patients with venous branch invasion have an outcome inferior to that of patients with pT1-2 disease. This confirms the adverse prognosis of venous branch invasion and supports pathological up-staging. The prognosis of venous branch invasion would be similar to that of renal vein invasion.

The presence of tumor necrosis, lymph nodal involvement and distant metastasis were the most powerful prognostic factors for survival in our patients with RCC.

The survival rate at 5 years was $82.5 \%$, $71.6 \%$ and $62.5 \%$ for our patients without tumor necrosis, with less than 50\% tumor necro- 
sis and more than 50\% tumor necrosis, respectively (Figure-2). In our study the percentage of tumor necrosis was an independent predictor of disease-free survival. While prior series showed that pathologically confirmed tumor necrosis is a marker of aggressive disease and decreased survival, (13-15) others failed to show an association with decreased survival. (16-18). In the largest series, Sengupta et al. (14) examined more than 3,000 patients who underwent partial or radical nephrectomy and found an association between the presence of tumor necrosis with decreased disease specific survival. On multivariate analysis controlling for stage, size and grade the presence of tumor necrosis conferred almost 2 times the risk of death from RCC. In another recent study, Katz et al. (19) identified tumor necrosis in 30\% of 841 patients. Those patients with 50\% or greater necrosis in the primary tumor were more than 2 times more likely to die of RCC when controlling for nuclear grade, subtype, stage, size and age than patients with less than 50\% TN. However, the presence or absence of TN alone failed to remain an independent predictor for survival.

A critical yet unresolved issue in the surgical management of RCC is the role and extent of lymphadenectomy. Some of the difficulty in recommending LN dissection is that there is no standardized and validated template to use. In addition, there is controversy regarding the definition of adequate regional or extended lymphadenectomy for patients undergoing nephrectomy. Whitson et al. (20) in a large series of patients showed an association between increased lymph node yield and improved disease specific survival of patients with lymph node positive nonmetastatic renal cell carcinoma who underwent lymphadenectomy. In our series, lymphadenectomy was performed in 130 of our patients of whom 22 had lymph node involvement. When lymph nodes were negative for malignancy, disease-free survival at 5 years was $80 \%$ while in patients with lymph node involvement, rate of disease-free survival dropped to $43.3 \%$. In patients in whom we had no access to the lymph nodes because the lymphadenectomy was not carried out, the rate of disease-free survival reached 70\% (Figure-3). Perhaps several of these patients should have positive lymph nodes which would explain this intermediate survival rate. Another hypothesis for the lower survival of this group of patients compared with patients with negative lymph nodes would be the removal of micrometastases, undetected by conventional histology, during the lymphadenectomy.

Regarding the presence of metastases, only $14 \%$ of patients who developed metastases were alive after 5 years (Figure-4). Several studies have identified various sites of metastatic disease to have prognostic significance; however, the number of involved sites appears to be a good surrogate for these individual sites. In multivariate analysis, the number of metastatic sites appears to be a strong independent prognostic factor (21).

\section{CONCLUSIONS}

Histological subtype $(\mathrm{p}=0.006)$, Fuhrman grade $(p<0.0001)$, tumor necrosis $(p=0.009)$, perinephric fat invasion ( $p=0.002)$, vascular embolization $(p=0.0002)$, presence of lymph node involvement ( $p<0.002)$, tumor size ( $p=0.0006)$, TNM stage ( $\mathrm{p}<0.00001)$ and presence of metastasis $(\mathrm{p}<0.00001)$ were significantly associated with death and/or progressive disease on univariate analysis. However, only histological subtype, tumor necrosis, lymph node involvement and presence of metastasis proved to be independent predictive variables of disease-free survival on multivariate analysis $(p=0.011,0.042,0.025$ and $\mathrm{p}<0.0001$, respectively). Therefore, the presence and rate of tumor necrosis should always be informed by the pathologist and lymphadenectomy should always be performed in all patients.

\section{CONFLICT OF INTEREST}

None declared.

\section{REFERENCES}

1. Jemal A, Siegel R, Ward E, Hao Y, Xu J, Thun MJ: Cancer statistics, 2009. CA Cancer J Clin. 2009; 59: 225-49.

2. Parkin DM, Bray F, Ferlay J, Pisani P. Global cancer statistics, 2002. CA Cancer J Clin. 2005; 55: 74-108. 
3. Brasil. Ministério da Saúde. Instituto Nacional de Câncer Estimativa 2010: incidência de câncer no Brasil. Instituto Nacional de Câncer. Rio de Janeiro, INCA, 2009; pp. 98

4. Nardi AC, Zequi Sde C, Clark OA, Almeida JC, Glina S: Epidemiologic characteristics of renal cell carcinoma in Brazil. Int Braz J Urol. 2010; 36: 151-7; discussion 158.

5. Van Poppel H, Becker F, Cadeddu JA, Gill IS, Janetschek $G$, Jewett MA, et al.: Treatment of localised renal cell carcinoma. Eur Urol. 2011; 60: 662-72.

6. Cheville JC, Lohse CM, Zincke H, Weaver AL, Blute ML: Comparisons of outcome and prognostic features among histologic subtypes of renal cell carcinoma. Am J Surg Pathol. 2003; 27: 612-24.

7. Patard JJ, Leray E, Rioux-Leclercq N, Cindolo L, Ficarra V, Zisman $A$, et al.: Prognostic value of histologic subtypes in renal cell carcinoma: a multicenter experience. J Clin Oncol. 2005; 23: 2763-71.

8. Thompson RH, Kurta JM, Kaag M, Tickoo SK, Kundu S, Katz D, et al.: Tumor size is associated with malignant potential in renal cell carcinoma cases. J Urol. 2009; 181: 2033-6.

9. Han KR, Bui MH, Pantuck AJ, Freitas DG, Leibovich BC, Dorey FJ, et al.: TNM T3a renal cell carcinoma: adrenal gland involvement is not the same as renal fat invasion. J Urol. 2003; 169: 899-903; discussion 903-4.

10. Thompson RH, Leibovich BC, Cheville JC, Webster WS, Lohse CM, Kwon ED, et al.: Is renal sinus fat invasion the same as perinephric fat invasion for pT3a renal cell carcinoma? J Urol. 2005; 174: 1218-21.

11. Anderson CB, Clark PE, Morgan TM, Stratton KL, Herrell $\mathrm{SD}$, Davis $\mathrm{R}$, et al.: Urinary collecting system invasion is a predictor for overall and disease-specific survival in locally invasive renal cell carcinoma. Urology. 2011; 78: 99-104.

12. Feifer A, Savage C, Rayala H, Lowrance W, Gotto G, Sprenkle $P$, et al.: Prognostic impact of muscular venous branch invasion in localized renal cell carcinoma cases. J Urol. 2011; 185: 37-42.

13. Ficarra V, Martignoni G, Lohse C, Novara G, Pea M, Cavalleri $S$, et al.: External validation of the Mayo Clinic Stage, Size, Grade and Necrosis (SSIGN) score to predict cancer specific survival using a European series of conventional renal cell carcinoma. J Urol. 2006; 175: 1235-9.
14. Sengupta S, Lohse CM, Leibovich BC, Frank I, Thompson $\mathrm{RH}$, Webster WS, et al.: Histologic coagulative tumor necrosis as a prognostic indicator of renal cell carcinoma aggressiveness. Cancer. 2005; 104: 511-20.

15. Thompson RH, Leibovich BC, Lohse CM, Cheville JC, Zincke $\mathrm{H}$, Blute $\mathrm{ML}$, et al.: Dynamic outcome prediction in patients with clear cell renal cell carcinoma treated with radical nephrectomy: the D-SSIGN score. J Urol. 2007; 177: 477-80.

16. Lam JS, Shvarts O, Said JW, Pantuck AJ, Seligson DB, AIdridge $M E$, et al:: Clinicopathologic and molecular correlations of necrosis in the primary tumor of patients with renal cell carcinoma. Cancer. 2005; 103: 2517-25.

17. Minervini A, Di Cristofano C, Gacci M, Serni S, Menicagli $M$, Lanciotti $M$, et al.: Prognostic role of histological necrosis for nonmetastatic clear cell renal cell carcinoma: correlation with pathological features and molecular markers. J Urol. 2008; 180: 1284-9.

18. Klatte T, Said JW, de Martino M, Larochelle J, Shuch B, Rao JY, et al.: Presence of tumor necrosis is not a significant predictor of survival in clear cell renal cell carcinoma: higher prognostic accuracy of extent based rather than presence/absence classification. J Urol. 2009; 181: 155864; discussion 1563-4.

19. Katz MD, Serrano MF, Grubb RL 3rd, Skolarus TA, Gao F, Humphrey PA, et al.: Percent microscopic tumor necrosis and survival after curative surgery for renal cell carcinoma. J Urol. 2010; 183: 909-14.

20. Whitson JM, Harris CR, Reese AC, Meng MV: Lymphadenectomy improves survival of patients with renal cell carcinoma and nodal metastases. J Urol. 2011; 185: 1615-20.

21. Bukowski RM. Prognostic factors for survival in metastatic renal cell carcinoma: update 2008. Cancer. 2009; 115(10 Suppl): 2273-81.

Correspondence address:

Dr. Antonio Augusto Ornellas Department of Urology Instituto Nacional de Câncer Praça da Cruz Vermelha, 23 Rio de Janeiro, RJ, 20230-130, Brazil

E-mail: ornellasa@hotmail.com 